vocational registration should be a body of the medical profession. It is not the business of the Government in the shape of the Health Department. The G.M.C. by tradition and experience is the obvious choice. But if it is to gain the confidence of the medical profession in its new task it should consider whether an organization that has served it well for so long is the right one for the future. Part at least of the suspicion and resentment that have greeted the G.M.C.'s proposals for retention fees and vocational registration has stemmed from the apparent secrecy with which it conducts its business. The B.M.A. has called for a majority of elected members on the G.M.C. At present 8 are nominated by the Privy Council, 28 are representatives of universities and the colleges, though the Royal College of General Practitioners is not yet among them, and 11 are elected by the profession. Doctors would certainly be happier if more members were directly elected and if the deliberations of the council were as open to reporting as are its disciplinary proceedings.

If, then, the G.M.C. becomes a little less remote, doctors should be prepared to let it extend its supervision of medical education and standards to the postgraduate sphere. Would they be willing to pay for it to do so ? There must be safeguards against lowering standards, since inadequate training programmes, timidly supervised, would be worse than the existing system. Specialty boards would need to be set up ; regular inspections would have to be made ; registers maintained. Only by the profession itself paying for the boards can the risk of them coming under Government control be prevented. Furthermore, this would give doctors the right to demand regular accounts of their activities from the boards; and the boards themselves would be free to take decisions which might be unpopular with the Government.

Vocational registration should lead to higher standards of practice in all fields of British medicine. Nevertheless, the profession would be wise not to accept any scheme unless the specialty boards have real power to reject substandard training posts, the necessary expansion of the consultant and other grades in the hospital service is guaranteed, and there is a greater measure of direct representation of the profession on the G.M.C.

\section{Maternal Rubella after the First Trimester}

Retrospective studies have shown that the risk of major congenital malformation following rubella acquired during the first trimester of pregnancy is about 20 to $35 \% .^{1-3}$ The highest incidence of defects occurs when rubella is contracted during the first four weeks of pregnancy, where it may approach a rate of 50 to $60 \%, 4$ and furthermore if contracted at an early stage the ensuing defects are frequently multiple. Thereafter the incidence gradually declines until after infection during the fourth month of pregnancy the incidence is about 4 to $5 \%$, approximately double the rate reported in pregnancies in which the mother is not infected.

Though a few cases of malformation have been reported as following rubella after the fourth month of pregnancy, ${ }^{156}$ it is generally held that the risk of them in late pregnancy is very low indeed. However, a recent report by Janet Hardy

\footnotetext{
1 British Medical fournal, 1965, 1, 537.
}

and her colleagues from the Johns Hopkins University is rather disquieting. ${ }^{7}$ They are conducting a long-term prospective epidemiological inquiry to assess the impact of the extensive 1964 rubella epidemic in the U.S.A. on approximately 1,350 pregnancies. In 24 cases they obtained clinical and serological evidence of infection by rubella virus after the first trimester, 19 of them after the 16th week from the estimated date of gestation. Among these 24 pregnancies there were two foetal deaths (infection occurring at 19 weeks in one case, virus being recovered from the placenta). But of the 22 live births, although abnormalities could rarely be detected in the babies at or soon after birth, only seven children could be considered completely normal when followed up for periods up to four years.

The clinical features of infection were rather more subtle than those following rubella in the first trimester. For example, gross lesions of eye and heart were rarely encountered, the principal anomalies consisting of hearing defects, retardation in physical, mental, and motor development, and associated difficulties in communication. Since infection occurred in these mothers well after the critical period of organogenesis, the clinical picture observed probably resulted from persistent viral replication during the remaining period of gestation. Indeed, since many of the infants were apparently normal at birth, it is likely that some of their disabilities were due to the continuance of virus replication during early infancy. Virological studies conducted on these infants showed that rubella virus could be recovered from the pharynx of only two (80 to $85 \%$ of infants infected in the first trimester excrete virus at birth), but ten had serological evidence of intrauterine infection.

Before any accurate assessment of the overall risk from rubella in late pregnancy can be made additional evidence from further studies must be collected, and this report indicates how important it is that this should be done and how valuable long-term surveillance is. Until accumulated data from such studies are available, it will be difficult to get a clear picture of the problem. In any case many obstetricians are reluctant to terminate pregnancy much after, say, 18 to 20 weeks. Furthermore, it is impossible at present to predict the ultimate prognosis of infants with less severe symptoms of congenitally acquired rubella. But it is encouraging to note that in a follow-up study on 50 well-documented patients who are now adults and who were congenitally infected during rubella epidemics in New South Wales in the 1940s almost all had made a good socio-economic adjustment in relation to predictions in early life. Indeed, many had married, and only four were not gainfully employed. ${ }^{8}$

What is important at present, because a diagnosis of rubella on clinical grounds alone is unreliable, is that laboratory investigations should be conducted on women who experience rubella-like illnesses during pregnancy; many will be

Lundström, R., Acta Paediatrica, 1962, 51, Supplement No. 133. Bradford-Hill, A Doll, R., Galloway, T. McL., and Hughes, J. P. W. British fournal of Preventive and Social Medicine, 1958, 12, 1 .

s Pitt, D., and Keir, E. H., Medical fournal of Australia, 1965, 2, 737.

4 Dudgeon, J. A., Archives of Disease in Childhood, 1967, 42, 110.

5 Gregg, N. M., Transactions of the Ophthalmological Society of Australia, 1941, 3, 35.

- Swan, C., Tostevin, A. L., and Black, G. H. B., Medical fournal of Australia, 1946, 2, 889.

7 Hardy, J. B., McCracken, G. H., jun., Gilkeson, M. R., and Sever, J. L., fournal of the American Medical Association, 1969 207, 2414.

8 Menser, M. A., Dods, L., and Harley, J. D., Lancet, 1967, 2, 1347.

9 Hillary, I. B., Meenan, P. N., Griffith, A. H., Draper, C. C., and Laurence, G. D., British Medical fournal, 1969, 2, 531.

10 British Medical fournal, 1969, 2, 527.

1 Proceedings of the 23rd International Symposium on Rubella Vaccines, 1969 , ed. R. H. Regamey. Basle, Karger. 
reassured to find out that their illness was not rubella. It is equally important that the infants of those mothers in whom the disease is virologically confirmed are followed up carefully over a prolonged period in order that early lesions may be sought. If they are present, every assistance and encouragement can then immediately be given to both the mother and her affected child. It is possible that the attenuated vaccines $^{9-11}$ which recently have been developed will go a long way to solving these problems before too long.

\section{Computers on the March}

For all the swift obedience with which computers reply to the questions put to them they remain exacting servants. Their initial costs are very high, the user may have to rearrange his working life to suit the computer he employs, and the equipment itself demands some understanding if its capabilities are to be fully brought out.

This week the B.M.A. Planning Unit publishes a report of a working party on computers in medicine. ${ }^{1}$ As well as reviewing the functions for which these instruments are suited it considers possible future applications. In this respect it is well timed to help medical men take part in the planning of computer services in their practice and administration, especially as it provides an excellent glossary of the technical terms essential to any informed discussion of these machines. Doctors need no longer puzzle over " high-level language," worry about the quality of "utility programmes," or reach for the D.D.T. when " debugging." But more important is the questioning this report should stimulate in its readers' minds on what function computers may have as adjuncts to the practice of medicine. According to the foreword many millions of pounds may be allocated for the provision of computers in the Health Service, and it comments: "This report will do little to allay the suspicions of some health service workers that the unsolicited generosity of Government in this matter may be intended primarily to serve the purposes of a national computer industry rather than the interests of the Health Service."

So far in Great Britain the computer has been set to a variety of tasks in the health services, some of which were discussed in a series of articles in the B.M.7. last year. ${ }^{2}$ They have won a place in pathology laboratories, ${ }^{34}$ proved to be exceedingly helpful in research entailing calculations on large quantities of data, improved the storage and retrieval of records, and facilitated the complex calculations needed in radiotherapy. In the monitoring of patients they find a place, and their use in hospital administration is growing. But growing too fast, according to Dr. J. H. Mitchell, who declares in his paper at page 157 this week that "the medical profession is in danger of being dazzled by optimistic claims about the usefulness of computers in case record processing."

To medical men as well as to their patients the safeguarding of professional secrecy must be paramount, and the report devotes some space to discussing its preservation if computers

1 Report of the Working Party on Computers in Medicine, British Medical Association Planning Unit Report No. 3, 1969. London, British Medical Association. Price 9s. 6d., including postage.

2 British Medical fournal, 1968, 2, 823; 3, 51;3, 116 ; 3, 180 ; 3, 247 ; 3, 309;3, 367

s Automation and Data Processing in Pathology, ed. T. P. Whitehead fournal of Clinical Pathology, 1969, Symposium Supplement No. 3, B.M.A. House.

- British Medical fournal, 1969, 3, 374.

$\checkmark$ Acheson, E. D., Medical Record Linkage, 1967. London, O.U.P. came into use to store medical information about individual patients under their names. To put various kinds of restrictions on the withdrawal of information from a computer is technically simple enough. It can thus be made available only to certain specified individuals, and this method of storing it could theoretically provide greater safeguards than exist at present. But anxiety lest the information might be subject to deliberate misuse is understandable. Could there be bank robbers working at these machines with blackmail in mind ? More cogent perhaps is the mistrust anyone may reasonably feel of governmental departments and agencies, or employers and other people in authority, learning more than was intended about a person owing to some simple oversight-or even by a change in the law. That formerly private store of personal information, a person's bank account, is now by law open to inspection by the Inland Revenue authorities. Experience with medical record linkage schemes ${ }^{5}$ so far is that the general public will co-operate, no doubt partly because the dedicated and enthusiastic doctors in charge have shown that safeguards are practicable and the scheme is for the individual's benefit. But on a scale so large that virtually the whole population would have their medical histories recorded for life in a computer-and perhaps after death too?-the official and impersonal character of the arrangements would be unlikely to enjoy the same compliance. The question would therefore have to be considered whether a person going to a doctor in the Health Service could refuse to have his record computerized.

But what must weigh heavily in any extension of computers in the health services is their high cost in relation to that of many other desperately needed improvements. The sort of equipment needed would range in price from about $£ 30,000$ for a machine doing a few specific tasks to about $£ 500,000$ for one capable of functioning more generally. Skilled staff must be employed to service it and the equipment be replaced after not very many years. The report suggests that a figure appropriate to the hospital service in this country over the next 15 years could be $£ 20$ to $£ 40$ million a year. Such figures give some basis to its comment on the financial consequences of computerization that "in practice, direct cost savings are not often demonstrable." Time certainly is saved, and this can be essential to a pathology laboratory faced with an ever growing demand for biochemical tests, for instance. And despite the bills for $£ 1$ million or so that some harassed householders claim to have received from their computerized gas boards the reduction of error is described in the report as " a very real benefit." On this, it suggests, the justification for automation may in the long run heavily depend. And the best prospect for effective use at reasonable cost and in reasonable time is " in replacing tedious, slow, and error-prone but conceptually simple human operations." This certainly cuts the computer down to size and helps to direct attention to those aspects of the management of patients where the computer can be a real aid to doctor, nurse, or clerk rather than a wonderful toy for which work must at all costs be found.

Dr. Henry Miller, introducing the report, states that if the Health Department has a policy on computers it is slow to expose it to expert examination or to public discussion. Clearly, enormous sums of public money are involved in the provision of this equipment. Staff will need to be trained to a high level of skill to operate it. Every practising doctor will need to acquire considerable understanding of what a computer service can and cannot provide, so that instruction on them will have to be offered at both under- 